\title{
High prevalence of hidradenitis suppurativa in patients with perianal fistula
}

\author{
Christine B. Ardon $^{1}$ (D) $\cdot$ Charlotte Molenaar $^{2} \cdot$ Kelsey R. van Straalen ${ }^{1} \cdot$ Violette C. Scholtes $^{1} \cdot$ Errol P. Prens ${ }^{1}$. \\ Hessel H. van der Zee ${ }^{1}$
}

Accepted: 2 May 2019 / Published online: 16 May 2019

(C) The Author(s) 2019

\begin{abstract}
Background Perianal fistula is an abnormal communication between the anal canal and perianal skin. Hidradenitis suppurativa (HS) is a chronic, auto-inflammatory skin disease in the intertriginous body areas, presenting with recurring abscesses, inflammatory nodules, and sinus tracts. The aim of this study was to determine the prevalence of HS in patients with a perianal fistula. Methods All patients with perianal fistula visiting a specialized proctology clinic between July and September 2017 were included and asked a validated diagnostic question for HS. Subsequently, physical examination was performed to objectively assess the diagnosis and relevant patient characteristics.

Results In 6.6\% (8/122) of patients, HS was diagnosed outside the perianal region. Four of these patients were newly diagnosed. The fistulas in HS patients were classified as a superficial fistula (three), a blind ending fistula (two), and a transsphincteric fistula (two). One patient had more than one type of fistula.

Conclusion The prevalence of HS in patients with a perianal fistula is at least $6.6 \%$. This is higher than the prevalence reported in the general European population (1\%) suggesting an association between perianal fistulas and HS. We stress the importance to screen for HS in patients with perianal fistulas in order to start appropriate anti-inflammatory treatment to reduce symptoms and disease progression.
\end{abstract}

Keywords Acne inversa $\cdot$ Sinus $\cdot$ Fistula $\cdot$ Tunnel $\cdot$ Abscess

\section{Introduction}

Perianal fistulas $(\mathrm{PF})$ are uncommon with an incidence varying from 1.04-2.23 patients per 10,000 persons per year [1]. PF are associated with considerable discomfort, morbidity, and decreased quality of life as patients can present with perianal pain, pruritus, bleeding, or purulent discharge [2]. Most frequently a PF is the result of a cryptoglandular anorectal abscess [3]. Other, less common causes comprise Crohn's disease, surgery, or trauma [3]. However, a fistula in the perianal region may also be a sign of the underdiagnosed, chronic, autoinflammatory skin disease hidradenitis suppurativa (HS). HS is characterized by recurrent abscesses, nodules, and draining fistulas in the intertriginous regions such as the axillae and

Christine B. Ardon

c.ardon@erasmusmc.nl

1 Department of Dermatology, Erasmus University Medical Center, Rotterdam, The Netherlands

2 Proctos Clinic, Bilthoven, The Netherlands inguinal areas but also the buttocks and perianal area. Anogenital involvement is fairly common and seen in $18.8 \%$ of HS patients [4]. The prevalence of HS in the European general population is approximately $1 \%$ with a male to female ratio of 1:3 [5]. The disease usually starts in the early twenties. Smoking and obesity are well-established risk factors for HS [5]. Even though HS is quite common and has a tremendous impact on the quality of life, it is still is relatively unknown for patients and physicians [6]. This results in a mean time to diagnosis of 7.2 years after consulting 3.9 health care professionals on average [6]. Since HS and PF can be clinically similar, the diagnosis of HS should be part of the differential diagnosis of perianal fistula. However, unfamiliarity with this diagnosis could mean that HS goes undiagnosed in a portion of the perianal fistula population. Therefore, the aim of this study was to evaluate the prevalence of HS in patients with PF.

\section{Methods}

All patients with a PF attending the specialized proctology clinic, Proctos, in Bilthoven, the Netherlands, between July 
and September 2017 were included. A validated diagnostic question for HS was used as a screening tool: "Have you ever had recurrent boils in your armpits, groins or on the buttocks except for the anus for the last six months?" [7]. Subsequently, all patients with a positive answer underwent physical examination of the axillary, inguinal, and perianal region to confirm the diagnosis of HS when nodules, abscesses, or sinus tracts were found. Subsequently, HS severity was classified according to the three-stage Hurley classification $[5,8]$. As part of the routine care in the Proctos Clinic, all perianal fistulas were examined using a three-dimensional endoanal ultrasound and classified according to the Parks classification [9]. The MannWhitney $U$ tests and Fisher's exact tests were performed to analyze the difference between patients with perianal fistulas with and without HS. Data were analyzed by use of SPSS software (IBM, version 24.0). This type of study is exempt from medical ethical committee approval under Dutch law.

\section{Results}

A total of 122 patients with a PF were included. Twelve patients $(9.8 \%)$ answered positively to the diagnostic HS question. Physical examination confirmed the diagnosis in eight of these patients, amounting to a prevalence of HS in patients with a perianal fistula of $6.6 \%$. Four out of eight patients had not previously been diagnosed with HS. Patient characteristics of patients with HS are presented in Table 1. All patients with HS were classified as Hurley II severity due to the presence of the perianal fistula. Four patients with HS had a positive family history (first degree) of the disease. Skin regions affected by HS included the perianal $(n=8)$, inguinal $(n=4)$, gluteal $(n=3)$, and axillary $(n=2)$ areas. Three of these HS patients presented with a superficial fistula, two with a blind ending fistula, and two with a transsphincteric fistula. One patient had more than one type of fistula. Patients with HS were more frequently smokers compared with patients without HS, respectively, $62.5 \%$ and $23.6 \%(p=0.03)$. Moreover, in four out of eight HS patients, a pilonidal sinus was present (Table 2).

\section{Discussion}

To our knowledge, this is the first study investigating the prevalence of HS in patients with PF. We found a prevalence of HS to be at least $6.6 \%$. This estimate might be higher (9.8\%) when incorporating the, possibly cases of mild, HS. Since mild HS can go in regression, it cannot be confirmed by physical examination. Four patients received a new diagnosis of HS, demonstrating the underdiagnoses of this disease. Early diagnosis of HS is important as it allows for early
Table 1 Characteristics of perianal fistula patients with HS

\begin{tabular}{|c|c|}
\hline $\mathrm{HS}, n(\%)$ & $8(6.6)$ \\
\hline \multicolumn{2}{|l|}{ Known history of HS, $n(\%)$} \\
\hline Yes & $4(93.8)$ \\
\hline No & $4(6.3)$ \\
\hline \multicolumn{2}{|l|}{ Family history of HS, $n(\%)$} \\
\hline First degree & $4(50)$ \\
\hline Second degree & $0(0)$ \\
\hline No family history of HS & $4(50)$ \\
\hline \multicolumn{2}{|l|}{ Hurley stadium, $n(\%)$} \\
\hline Stadium I & $0(0)$ \\
\hline Stadium II & $8(100)$ \\
\hline Stadium III & $0(0)$ \\
\hline \multicolumn{2}{|l|}{ Affected body regions, $n(\%)$} \\
\hline Inguinal region & $3(37.50)$ \\
\hline Gluteal region & $2(25)$ \\
\hline Axillary region & $1(12.50)$ \\
\hline Perineal region & $2(25)$ \\
\hline \multicolumn{2}{|l|}{ Pseudocomedones, $n(\%)$} \\
\hline Inguinal region & $2(25)$ \\
\hline Gluteal region & $1(12.50)$ \\
\hline Axillary region & $2(25.50)$ \\
\hline Perineal region & $0(0)$ \\
\hline \multicolumn{2}{|l|}{ Perianal fistula, $n(\%)$} \\
\hline Transsphincteric (high perianal fistula) & $2(25)$ \\
\hline More than one (high perianal fistula) & $1(12.5)$ \\
\hline Superficial & $3(37.5)$ \\
\hline Blind fistula & $2(25)$ \\
\hline
\end{tabular}

treatment with anti-inflammatory medication, which may reduce symptoms and delay of natural disease progression. Since the presumed prevalence of HS in the general population is $1 \%$, we argue that there may be an association between HS and PF [6]. However, whether PF is the result of HS or that $\mathrm{PF}$ is a distinct entity present next to HS, with a similar pathogenic mechanism, remains unknown. HS sinus tracts usually do not penetrate the anal sphincter. We argue that the PF found in the majority of our patients represent a HS-related sinus tract rather than a separate entity. Interestingly, most patients that were found to have HS were male. Even though HS predominantly affects women, it is known that HS with anogenital involvement is most frequent in men [4]. Strengths of this study are the use of a validated HS diagnostic question in combination with physical examination in order to diagnose HS as the use of three-dimensional endoanal ultrasound for a more precise classification. Future research should investigate $\mathrm{PF}$ in $\mathrm{HS}$ patients versus non-HS patients using histology. In conclusion, we demonstrate an underdiagnosis of HS in patients presenting with perianal fistulas, emphasizing the importance of asking patients for HS symptomatology and subsequent physical examination of the intertriginous regions. 
Table 2 Patient characteristics perianal fistulas with or without HS

\begin{tabular}{llll}
\hline & Perianal fistula with HS $(n=8)$ & Perianal fistula without HS $(n=114)$ & $p$ value \\
\hline Sex, $n(\%)$ & & & $71(62.3)$ \\
$\quad$ Male & $6(75)$ & $43(37.7)$ & 0.71 \\
Female & $2(25)$ & $46.0(36.3-53.5)$ & 0.35 \\
Age (years), median (IQR) & $41.0(36.5-47.0)$ & $43.0(33.8-51.0)$ & 0.36 \\
Age of onset HS (years), median (IQR) & $40.0(29.3-44.8)$ & $25.5(23.0-27.7)$ & 0.32 \\
Body mass index, median (IQR) & $26.6(24.2-33.2)$ & $25(23.6)$ & $0.03 * *$ \\
Smoker, $n(\%)$ & $5(62.5)$ & $2(1.9)$ & $0.00001^{* *}$ \\
Pilonidal sinus, $n(\%)$ & $4(50)$ & $28(27.2)$ & $0.04 * *$ \\
Fissure, $n(\%)$ & $5(62.5)$ & $2(1.9)$ & 0.2 \\
Crohn's disease, $n(\%)$ & $1(12.5)$ & \\
\hline
\end{tabular}

In all continuous variables: Mann-Whitney $U$ Test. Nominal variables: Fisher's exact test

**Statistically significant result

Open Access This article is distributed under the terms of the Creative Commons Attribution 4.0 International License (http:// creativecommons.org/licenses/by/4.0/), which permits unrestricted use, distribution, and reproduction in any medium, provided you give appropriate credit to the original author(s) and the source, provide a link to the Creative Commons license, and indicate if changes were made.

\section{References}

1. Zanotti C, Martinez-Puente C, Pascual I, Pascual M, Herreros D, García-Olmo D (2007) An assessment of the incidence of fistulain-ano in four countries of the European Union. Int J Color Dis 22(12):1459-1462

2. Owen HA, Buchanan GN, Schizas A, Cohen R, Williams AB (2016) Quality of life with anal fistula. Ann R Coll Surg Engl 98(5):334-338

3. Sugrue J, Nordenstam J, Abcarian H, Bartholomew A, Schwartz JL, Mellgren A, Tozer PJ (2017) Pathogenesis and persistence of cryptoglandular anal fistula: a systematic review. Tech Coloproctol 21(6):425-432

4. Schrader AM, Deckers IE, van der Zee HH, Boer J, Prens EP (2014) Hidradenitis suppurativa: a retrospective study of 846 Dutch patients to identify factors associated with disease severity. J Am Acad Dermatol 71(3):460-467. https://doi.org/10.1016/j.jaad.2014.04.001

5. Zouboulis CC, Del Marmol V, Mrowietz U, Prens EP, Tzellos T, Jemec GBE (2015) Hidradenitis suppurativa/acne inversa: criteria for diagnosis, severity assessment, classification and disease evaluation. Dermatology 231(2):184-190
6. Saunte DM, Boer J, Stratigos A, Szepietowski JC, Hamzavi I, Kim KH, Zarchi K, Antoniou C, Matusiak L, Lim HW, Williams M, Kwon HH, Gurer MA, Mammadova F, Kaminsky A, Prens E, van der Zee HH, Bettoli V, Zauli S, Hafner J, Lauchli S, French LE, Riad H, El-Domyati M, Abdel-Wahab H, Kirby B, Kelly G, Calderon P, Del Marmol V, Benhadou F, Revuz J, Zouboulis CC, Karagiannidis I, Sartorius K, Hagstromer L, McMeniman E, Ong N, Dolenc-Voljc M, Mokos ZB, Borradori L, Hunger RE, Sladden C, Scheinfeld N, Moftah N, Emtestam L, Lapins J, Doss N, Kurokawa I, Jemec GB (2015) Diagnostic delay in hidradenitis suppurativa is a global problem. Br J Dermatol 173(6):1546-1549. https://doi.org/10.1111/bjd. 14038

7. Esmann S, Dufour D, Jemec G (2010) Questionnaire-based diagnosis of hidradenitis suppurativa: specificity, sensitivity and positive predictive value of specific diagnostic questions. Br J Dermatol 163(1):102-106

8. Hurley H (1989) Axillary hyperhidrosis, apocrine bromhidrosis, hidradenitis suppurativa, and familial benign pemphigus: surgical approach. In: Roenigk RK, Roenigk HH (eds) Roenigk and Roenigk's dermatologic surgery: principles and practice. Marcel Dekker, New York

9. Parks AG, Gordon PH, Hardcastle JD (1976) A classification of fistula-in-ano. Br J Surg 63(1):1-12

Publisher's note Springer Nature remains neutral with regard to jurisdictional claims in published maps and institutional affiliations. 